OPEN ACCESS

Edited by:

Liming Dai,

Case Western Reserve University,

United States

Reviewed by:

Lola González-García,

Leibniz Institut für Neue Materialien

(LG), Germany

Josep Albero,

Instituto de Tecnología Química (ITQ),

Spain

*Correspondence:

Ming-Chung Wu

mingchungwu@cgu.edu.tw

Specialty section:

This article was submitted to

Translational Materials Science,

a section of the journal

Frontiers in Materials

Received: 06 December 2018

Accepted: 20 March 2019

Published: 12 April 2019

Citation:

Chan S-H, Chang $Y-H$ and Wu M-C (2019) High-Performance Perovskite

Solar Cells Based on

Low-Temperature Processed Electron

Extraction Layer. Front. Mater. 6:57.

doi: 10.3389/fmats.2019.00057

\section{High-Performance Perovskite Solar Cells Based on Low-Temperature Processed Electron Extraction Layer}

\author{
Shun-Hsiang Chan ${ }^{1}$, Yin-Hsuan Chang ${ }^{1}$ and Ming-Chung $W^{1,2,3 *}$ \\ ${ }^{1}$ Department of Chemical and Materials Engineering, Chang Gung University, Taoyuan, Taiwan, ${ }^{2}$ Green Technology Research \\ Center, Chang Gung University, Taoyuan, Taiwan, ${ }^{3}$ Division of Neonatology, Department of Pediatrics, Chang Gung Memorial \\ Hospital, Taoyuan, Taiwan
}

Organic-inorganic perovskite solar cells (PSCs) is considered one of the most promising energy harvesting technologies due to its high power conversion efficiency (PCE). The T. Miyasaka group first reported the methylammonium lead halide $\left(\mathrm{CH}_{3} \mathrm{NH}_{3} \mathrm{PbX}\right.$ ) as a light absorber of dye-sensitized solar cells with a PCE of 3.8\% in 2009. Over the past decade, many research groups have been dedicated to constructing high-performance PSCs and have obtained fantastic progress. Before commercialization, many issues have to be overcome. To extend the application of PSCs, flexible PSCs are seen as the preferred choice. However, the conventional process requires high-temperature procedures that are incompatible with the production of flexible PSCs. Here, we specifically focus on the recent developments of the low-temperature process strategies for fabricating high-performance PSCs. This mini-review briefly discusses the development in low-temperature processed metal oxide and carbon-based electron extraction layer (EEL). The approaches for low-temperature solution-processed PSCs are introduced and then the various PSCs with distinctive EEL are discussed. Overall, this minireview contributes to a better understanding of the low-temperature processed electron extraction layer. Strategies and perspectives are also provided for further high-performance PSCs.

Keywords: perovskite solar cell, low-temperature process, electron extraction layer, metal oxide, power conversion efficiency

\section{INTRODUCTION}

The issue of energy crisis has received increasing attention in recent years. Researchers from all over the world have been focusing on the development of renewable energy, such as wind, geothermal, biomass, and solar energy, etc. Solar energy is less costly among renewable energy, it is predictable compared with wind energy, and is less site-dependent. Hence, solar energy technology has flourished in recent years. From first-generation poly/monocrystalline silicon solar cell, secondgeneration thin-film solar cell to third-generation solution-processed solar cell, the manufacturing cost has been significantly reduced. Third-generation solution-processed solar cells include organic photovoltaic (OPV), dye-sensitized solar cell (DSSC), and perovskite solar cell (PSC). Currently, PSC exhibits a power conversion efficiency (PCE) of as high as $23.7 \%$ in 2019. The typical perovskite structure is $\mathrm{ABX}_{3}$, where $\mathrm{A}$ is a monovalent cation [e.g., methylammonium (MA), formamidinium (FA), cesium (Cs), and rubidium ( $\mathrm{Rb})$ ], $\mathrm{B}$ is a divalent cation [e.g., lead $(\mathrm{Pb})$ and tin $(\mathrm{Sn})$ ], and $\mathrm{X}$ is a halide [e.g., chlorine (Cl), bromine (Br), and iodine (I)] (Liu et al., 2016; Saliba et al., 2016a,b). 
Furthermore, the structure is based on A-site cation occupying a cuboctahedral site with $\mathrm{BX}_{6}$ octahedra. The octahedron will connect with each other, and the center of each octahedron is the location of A cation. The PSC structure can be divided into two types, including $\mathrm{p}-\mathrm{i}-\mathrm{n}$ and $\mathrm{n}-\mathrm{i}-\mathrm{p}$ structures (Figures 1A,B). The p-i-n structured PSC is based on the organic solar cells having ITO/p-type material (HTL)/perovskite/n-type material (EEL)/metal electrode (Heo et al., 2015; Fan et al., 2018; Mali et al., 2018). In contrast, n-i-p structured PSC is adopted to construct DSSC with structure FTO/n-type material (EEL)/perovskite/p-type material (HTL)/metal electrode (Chan et al., 2017; Wu et al., 2018a). Many n-type materials, including $\mathrm{TiO}_{2}, \mathrm{Al}_{2} \mathrm{O}_{3}, \mathrm{ZnO}, \mathrm{ZrO}_{2}$, and $\mathrm{SnO}_{2}$, are often used as electron extraction layer (EEL) for PSC due to the appropriate energy band alignment with perovskite absorber (Anaraki et al., 2016; Che et al., 2016; Zhang et al., 2017, 2018; Wu et al., 2018a). However, the synthesis of metal oxides often requires hightemperature treatment to increase the crystallinity. Therefore, developing metal oxides for EEL through the low-temperature process is imperative. For the flexible PSC, the processing temperature is usually lower than $150^{\circ} \mathrm{C}$. The low-temperature process can effectively reduce production cost and increase the feasibility of mass-production (e.g., roll-to-roll manufacturing) (Dou et al., 2018). The photovoltaic characteristic of PSC based on various EELs prepared by the low-temperature process are shown in Table 1. In this mini-review, we briefly introduce the development of the low-temperature processed metal oxide and carbon-based EEL for state-of-the-art PSC. Moreover, we also compared the PSC made by the high-temperature process to the ones made by the low-temperature process.

\section{LOW-TEMPERATURE $\mathrm{TIO}_{2}$ ELECTRON EXTRACTION LAYER}

For n-i-p structured perovskite device, $\mathrm{TiO}_{2}$ is often used as EEL due to the chemical stability, low-cost, and high charge transportability (Figure 1C). The minimum conduction band of $\mathrm{TiO}_{2}$ is lower than that of perovskite absorber, so that the electron can be effectively transported from perovskite absorber to $\mathrm{TiO}_{2}$ EEL. Moreover, the maximum valence band of $\mathrm{TiO}_{2}$ is also lower than that of perovskite absorber, resulting in the excellent hole blocking capability (Wu et al., 2016). For the $\mathrm{TiO}_{2}$-based EEL, it can be classified into two types, mesoporous-structured $\mathrm{TiO}_{2}$ layer and $\mathrm{TiO}_{2}$ compact layer (Wu et al., 2018b; Chen et al., 2019). The mesoporous-structured $\mathrm{TiO}_{2}$ layer must be calcined at above $400^{\circ} \mathrm{C}$ to remove the organic binder (e.g., ethyl cellulose) and form the porous structure (Wu et al., 2018a). However, the high-temperature calcination leads to cost increment and energy consumption, and it is not conducive to the low-temperature process. Therefore, the low-temperature process to prepare the nanostructure $\mathrm{TiO}_{2}$ layer has been regarded as a breakthrough. The low-temperature processed $\mathrm{TiO}_{2}$ as the EEL of PSC can be prepared by pulsed laser deposition. A laser beam was used to sublime a $\mathrm{TiO}_{2}$ target. Subsequently, the sublimed $\mathrm{TiO}_{2}$ films were deposited onto an ITO substrate at $300^{\circ} \mathrm{C}$. The hierarchical $\mathrm{TiO}_{2}$ nanostructures can effectively increase the contact area with perovskite absorber. Therefore, the interface between hierarchical $\mathrm{TiO}_{2} \mathrm{EEL} /$ perovskite absorber exhibits high electron-hole pair separation and electron extraction behavior. The PSC based on hierarchical $\mathrm{TiO}_{2}$ EEL has demonstrated a PCE of 14.1\% (Yang et al., 2016).

The low-temperature processed $3 \mathrm{D}$ flower-like $\mathrm{TiO}_{2}$ array is also an alternative EEL for high-performance PSC. The $\mathrm{TiO}_{2}$ array layer was deposited on an FTO substrate by chemical bath deposition method. In this process, the FTO glass was immersed in an $80^{\circ} \mathrm{C} \mathrm{TiCl}_{3} / \mathrm{HCl}$ solution for 4 to $10 \mathrm{~h}$ in a furnace. Subsequently, the $\mathrm{TiO}_{2}$ array layer was washed and dried at $100^{\circ} \mathrm{C}$ for $2 \mathrm{~h}$. The light-harvesting efficiency of the perovskitecoated $\mathrm{TiO}_{2}$ array increases with increasing chemical bath deposition reaction time of the $3 \mathrm{D}$ flower-like $\mathrm{TiO}_{2}$ array EEL. This is beneficial for obtaining a full coverage of the perovskite absorber layer. The flower-like $\mathrm{TiO}_{2}$ nanorods is anatase phase, and it shows the high light-harvesting and low recombination rate. The PSCs based on flower-like $\mathrm{TiO}_{2}$ nanorods EEL has shown a PCE of $15.7 \%$ with high reproducibility and less hysteresis (Supplementary Figure 1A) (Chen et al., 2016).

The pin-hole free compact $\mathrm{TiO}_{2}$ can be coated on FTO substrate with high coverage by the vacuum electron beam evaporation technique. For the mesoporous $\mathrm{TiO}_{2}$ layer, it was fabricated by spin-coating method, followed by a UV treatment for $200 \mathrm{~min}$. UV irradiation is used to remove the organic binders to form mesoporous scaffold. This work uses a full lowtemperature process to prepare compact $\mathrm{TiO}_{2}$ and mesoporous $\mathrm{TiO}_{2}$ layer. For J-V curve measurement, the champion device reached a stabilized efficiency of $18.2 \%$ under AM 1.5G solar simulator light (Supplementary Figure 1A). This research has carried all requirements for high-efficiency perovskite/silicon tandem cell with the full low-temperature process (Schulze et al., 2017).

The planar PSC fabricated by the low-temperature process can reach a PCE $>20 \%$. The deep trap states present at the perovskite absorber/EEL interface can hinder the photovoltaic performance. Many literatures have indicated that passivating the perovskite absorber/EEL interface can efficiently suppress deep trap states. Chlorine-capped $\mathrm{TiO}_{2} \mathrm{EEL}$ is able to reduce interface recombination at $\mathrm{TiO}_{2}$ /perovskite absorber interface. Chlorinecapped $\mathrm{TiO}_{2}$ nanocrystals was fabricated by the modified nonhydrolytic sol-gel method. The precursor solution was spincoated on FTO glass, then annealed in $150^{\circ} \mathrm{C}$ ambient air for $30 \mathrm{~min}$. The chloride added into perovskite absorber can enhance grain boundary passivation in perovskite device. This type of planar PSC has exhibited a high PCE of $20.1 \%$ without J-V hysteresis (Supplementary Figure 1A) (Tan et al., 2017).

\section{LOW-TEMPERATURE ZnO ELECTRON EXTRACTION LAYER}

$\mathrm{ZnO}$ is a low-cost n-type semiconductor having a bandgap of $3.3 \mathrm{eV}$ (Gaspar et al., 2017). $\mathrm{ZnO}$ can replace $\mathrm{TiO}_{2}$ as an EEL for PSC due to its higher electron mobility and suitable energy structure. Also, $\mathrm{ZnO}$ has a beneficial conduction band position at $4.4 \mathrm{eV}$, which is lower than LUMO of perovskite absorber. 


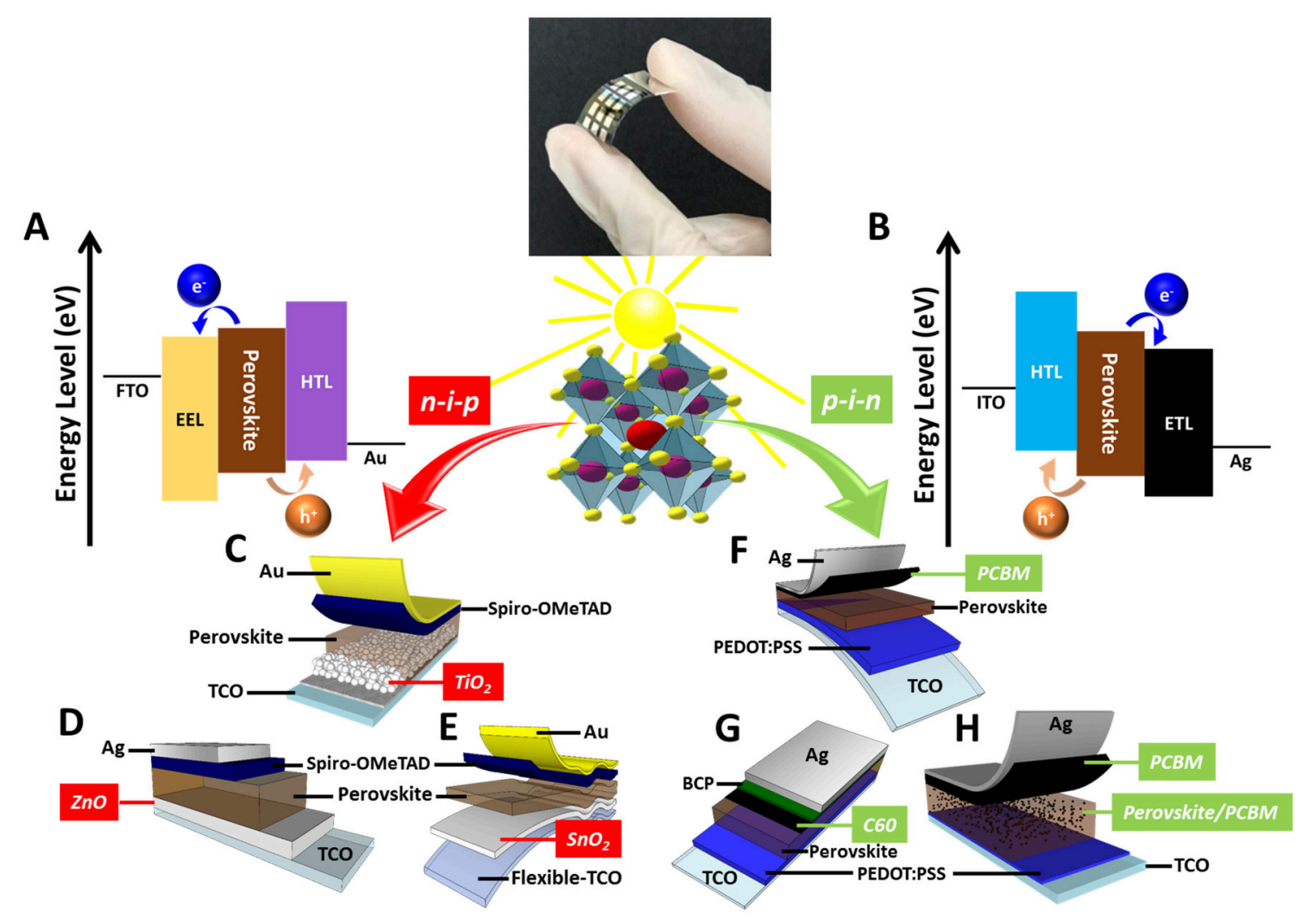

FIGURE 1 | Schematic diagram of (A,B) energy level, (C-H) device structure of PSC prepared by low-temperature process.

Therefore, $\mathrm{ZnO}$ has shown to play a critical role in improving the performance of PSC (Song et al., 2017). Especially, the fabricating temperature of $\mathrm{ZnO}$ film as EEL has been reduced to below $150^{\circ} \mathrm{C}$ (Figure 1D). The sol-gel $\mathrm{ZnO}$ was spin coated on ITO substrate, then annealed at $140^{\circ} \mathrm{C}$. The optical property, surface morphology, and crystal structure of $\mathrm{ZnO}$ film can be tuned by adjusting thickness. The results have shown that the multilayer $\mathrm{ZnO}$ film with high optical transmittance can increase the light absorption in perovskite absorber. After the thickness optimization of $\mathrm{ZnO}$ film, $\mathrm{ZnO}$ exhibits homogeneous surface morphology for the increment of perovskite crystal growth and suppression of deep trap states at the $\mathrm{ZnO}$ film/perovskite absorber interface. The PCE of PSC with $\mathrm{ZnO}$ film has reached 8.8\% (Supplementary Figure 1B) (Mahmud et al., 2017).

To reduce the surface defects of the $\mathrm{ZnO}$, chemical alkalimetal ( $\mathrm{Li}, \mathrm{Na}$, and $\mathrm{K}$ ) doping method has been adopted to passivate surface defect resulting in electron mobility enhancement and in raising the Fermi level. Doping metal ion into the semiconductor has been regarded as an effective strategy for electronic structure change. The alkali-metal doped $\mathrm{ZnO}$ EEL was prepared by dipping $\mathrm{ZnO}$ films into various $100^{\circ} \mathrm{C}$ alkali-metal hydroxide solutions for $10 \mathrm{~min}$. Successfully doping alkali-metal ion into the low-temperature processed $\mathrm{ZnO}$ can simultaneously passivate surface defects. The performance of PSC with various alkali-metal doped $\mathrm{ZnO}$ EEL has shown to be higher than that with non-doped $\mathrm{ZnO}$ EEL. The
PSC with K-doped ZnO EEL has achieved a PCE of 19.9\% without significant J-V hysteresis (Supplementary Figure 1B) (Azmi et al., 2018).

\section{LOW-TEMPERATURE $\mathrm{SnO}_{2}$ ELECTRON EXTRACTION LAYER}

$\mathrm{J}-\mathrm{V}$ hysteresis in $\mathrm{n}-\mathrm{i}-\mathrm{p}$ planar PSC remains a challenge for the advancement of such material. The hysteresis can lead to misjudgment of photovoltaic performance because the forward and reverse scans show different results. Recently, $\mathrm{SnO}_{2}$ has been reported as EEL of perovskite device that could eliminate J$\mathrm{V}$ hysteresis in planar structure PSC due to its large bandgap $(3.6 \mathrm{eV})$, higher electron mobility, optimal band alignment with perovskite absorber, and excellent electron extraction capability (Chen et al., 2018). $\mathrm{SnO}_{2}$ has shown high conductivity without high-temperature calcination treatment, thus beneficial for the preparation of flexible PSC (Figure 1E).

For the band structure of $\mathrm{SnO}_{2}$, it shows a lower conduction band and higher electron mobility compared to $\mathrm{TiO}_{2}$ EEL. Tuning the band alignment between $\mathrm{SnO}_{2}$ and perovskite absorber can facilitate charge transfer from perovskite absorber to $\mathrm{SnO}_{2}$ EEL and reduce charge accumulation. Applying the lowtemperature solution-processed $\mathrm{SnO}_{2}$ as EEL can maintain highperformance for PSC. The $\mathrm{SnO}_{2}$ precursor solution was prepared 
TABLE 1 | List of state-of-the-art PSC based on EEL prepared by the low-temperature process.

\begin{tabular}{|c|c|c|c|c|c|c|c|c|}
\hline $\begin{array}{l}\text { Device } \\
\text { structure }\end{array}$ & EEL & $\begin{array}{l}\text { Processing } \\
\text { temp. }\left({ }^{\circ} \mathrm{C}\right)\end{array}$ & Fabrication method & $\mathrm{J}_{\mathrm{sc}}\left(\mathrm{mA} / \mathrm{cm}^{2}\right)$ & Voc $_{\text {(volts) }}$ & FF (\%) & PCE (\%) & References \\
\hline \multirow[t]{14}{*}{$n-i-p$} & $\mathrm{TiO}_{2}$ & 80 & Chemical bath deposition & 22.0 & 0.99 & 72.0 & 15.7 & Chen et al., 2016 \\
\hline & & 120 & Evaporation/UV Treatment & 21.3 & 1.07 & 84.0 & 19.1 & Schulze et al., 2017 \\
\hline & & 150 & Spin-Coating & 22.3 & 1.19 & 80.6 & 21.4 & Tan et al., 2017 \\
\hline & & 300 & Pulsed laser deposition & 20.1 & 1.01 & 69.0 & 14.1 & Yang et al., 2016 \\
\hline & $\mathrm{ZnO}$ & 140 & Spin-Coating & 14.9 & 0.93 & 62.7 & 8.8 & Mahmud et al., 2017 \\
\hline & & 130 & Spin-Coating & 23.0 & 1.13 & 77.1 & 19.9 & Azmi et al., 2018 \\
\hline & & 150 & Spin-Coating & 22.6 & 1.11 & 75.3 & 18.9 & Song et al., 2017 \\
\hline & $\mathrm{SnO}_{2}$ & 150 & Spin-Coating & 24.9 & 1.09 & 75.7 & 20.5 & Jiang et al., 2016 \\
\hline & & $\approx \mathrm{RT}$ & Spin-Coating $/ \mathrm{N}_{2}$ Plasma treatment & 21.8 & 1.12 & 83.0 & 20.3 & Subbiah et al., 2018 \\
\hline & & 180 & Spin-Coating & 21.9 & 1.13 & 78.0 & 19.4 & Bu et al., 2018 \\
\hline & & 200 & Atomic layer deposition & 22.1 & 1.08 & 75.0 & 17.8 & Kuang et al., 2018 \\
\hline & WOx & 150 & Spin-Coating & 21.8 & 0.71 & 58.0 & 9.0 & Wang et al., 2015 \\
\hline & $\mathrm{CeO} x$ & 150 & Spin-Coating & 23.3 & 1.06 & 69.1 & 17.0 & Wang et al., 2017b \\
\hline & $\mathrm{Nb}_{2} \mathrm{O}_{5}$ & $\approx \mathrm{RT}$ & RF Magnetron sputtering technique & 22.9 & 1.04 & 72.0 & 17.1 & Ling et al., 2017 \\
\hline \multirow[t]{4}{*}{$p-i-n$} & PCBM & 100 & Spin-Coating & 21.8 & 1.04 & 78.0 & 17.8 & Zhou et al., 2018 \\
\hline & PCBM (BHJ) & 100 & Spin-Coating & 21.8 & 1.00 & 73.3 & 16.2 & Chang et al., 2018 \\
\hline & & 100 & Spin-Coating & 20.2 & 0.97 & 82.0 & 16.0 & Chiang and Wu, 2016 \\
\hline & $\mathrm{C} 60$ & $\approx \mathrm{RT}$ & Thermal evaporation & 22.3 & 1.08 & 75.9 & 18.2 & Liu et al., 2018 \\
\hline
\end{tabular}

$R T$, room temperature; $B H J$, bulk heterojunction; $R F$, radio frequency.

by diluting $\mathrm{SnO}_{2}$ aqueous solution. The precursor solution was spin coated onto ITO substrates, then annealed on a $150^{\circ} \mathrm{C}$ hot plate for $30 \mathrm{~min}$. $\mathrm{SnO}_{2}$ EEL has been further constructed with the perovskite absorber by introducing an excess $\mathrm{PbI}_{2}$ phase, passivating the traps in perovskite. This has achieved the best PCE of $20.5 \%$ without J-V hysteresis (Supplementary Figure 1C) (Jiang et al., 2016).

The low power nitrogen plasma treatment has been used to fabricate the low-temperature processed $\mathrm{SnO}_{2}$ EEL. The $\mathrm{SnO}_{2}$ precursor solution was prepared by dissolving $\mathrm{SnCl}_{4} \cdot 5 \mathrm{H}_{2} \mathrm{O}$ in IPA followed by continuous stirring for $2 \mathrm{~h}$. The precursor solution was spin coated on rigid FTO or PETITO. Then, the samples were treated by low power RF plasma under nitrogen gas flow. Nitrogen plasma induces the initial cleavage of metal alkoxy and hydroxyl groups, resulting in the formation of the Sn-O-Sn framework. The PCE of PSC based on nitrogen plasma threated $\mathrm{SnO}_{2}$ EEL has achieved $20.3 \%$ for rigid FTO substrates and $18.1 \%$ for flexible PSC (Supplementary Figure 1C) (Subbiah et al., 2018).

Atomic layer deposition is a deposition technique for highquality film fabrication. Highly transparent amorphous $\mathrm{SnO}_{2}$ was manufactured in atomic layer deposition reactor by lowtemperature process $\left(<200^{\circ} \mathrm{C}\right)$. The high-quality $\mathrm{SnO}_{2}$ film exhibited high electron mobility $\left(36 \mathrm{~cm}^{2} / \mathrm{V} \bullet\right.$ s). The PCE of PSC with deposition temperature of 50 and $200^{\circ} \mathrm{C} \mathrm{SnO}_{2}$ has reached 17.5 and $17.8 \%$, respectively (Kuang et al., 2018).

The PSC modules based on the low-temperature synthesized crystalline $\mathrm{SnO}_{2}$ have been studied. The electron transport resistance of $\mathrm{SnO}_{2}$ and charge recombination at EEL/perovskite absorber interface have been significantly decreased by thermal and UV-ozone treatments. The reported optimal thermal temperature for rigid PSC is $180^{\circ} \mathrm{C}$, and can be decreased to $120^{\circ} \mathrm{C}$ for flexible PSC. The PCE of rigid PSC, flexible PSC, and $5 \times 5 \mathrm{~cm}^{2}$ flexible module have achieved 19.4, 16.5, and $12.4 \%$, respectively (Supplementary Figure 1C) (Bu et al., 2018).

\section{OTHER METAL OXIDE ELECTRON EXTRACTION LAYER}

Tungsten oxide $\left(\mathrm{WO}_{\mathrm{x}}\right)$ is n-type semiconductors with wide bandgap (2.0-3.0 eV) and high electron mobility (10-20 $\left.\mathrm{cm}^{2} / \mathrm{V} \bullet \mathrm{s}\right)$. These excellent properties make $\mathrm{WO}_{\mathrm{x}}$ suitable as an EEL for perovskites photovoltaics. For the preparation of $\mathrm{WO}_{\mathrm{x}}$ solution, tungsten hexachloride and n-propanol were mixed together, then the $\mathrm{WO}_{\mathrm{x}}$ solution was spin coated on FTO. The amorphous $\mathrm{WO}_{\mathrm{x}}$ EEL prepared by low-temperature solution process $\left(150^{\circ} \mathrm{C}\right)$ shows higher electrical conductivity compared to $\mathrm{TiO}_{2}$. Moreover, the excited electrons in perovskite absorber have shown to transfer more efficiently from perovskite absorber to $\mathrm{WO}_{\mathrm{x}}$ EEL. Therefore, the short-circuit current density of PSC with $\mathrm{WO}_{\mathrm{x}}$ EEL has shown to be higher than that of PSC with $\mathrm{TiO}_{2}$ EEL. The PSC with $\mathrm{WO}_{\mathrm{x}}$ EEL has shown an average PCE of 9.0\% (Supplementary Figure 1D) (Wang et al., 2015).

Niobium oxide $\left(\mathrm{Nb}_{2} \mathrm{O}_{5}\right)$ exhibits high electronic properties and high chemical stability. Therefore, $\mathrm{Nb}_{2} \mathrm{O}_{5}$ has also been seen as a candidate material for EEL. The amorphous $\mathrm{Nb}_{2} \mathrm{O}_{5}$ was fabricated at room temperature by a facile radio frequency magnetron sputtering technique on a $\mathrm{Nb}_{2} \mathrm{O}_{5}$ target in an argon atmosphere. The room-temperature sputtered $\mathrm{Nb}_{2} \mathrm{O}_{5}$ was successfully used as the EEL for planar PSC. The amorphous $\mathrm{Nb}_{2} \mathrm{O}_{5}$ film is highly transparent under visible region. As a 
results, the PSC with the amorphous $\mathrm{Nb}_{2} \mathrm{O}_{5}$ EEL has exhibited a PCE of 17.2\% (Supplementary Figure 1D) (Ling et al., 2017).

Cerium oxide $\left(\mathrm{CeO}_{\mathrm{x}}\right)$ demonstrates wide bandgap, good transparency, large dielectric constant, and high chemical stability. $\mathrm{CeO}_{\mathrm{x}}$ film was fabricated by sol-gel and spin-coating method at low temperature $\left(150^{\circ} \mathrm{C}\right)$. The PSCs with $\mathrm{CeO}_{\mathrm{x}}$ film showed high performance and high stability. Then the PCE of PSC with $\mathrm{CeO}_{\mathrm{x}}$ film increased from 14.32 to $17.04 \%$ by [6,6]-phenyl C61 butyric acid methyl ester (PCBM) insertion (Supplementary Figure 1D) (Wang et al., 2017b).

\section{FULLERENE COMPOUNDS ELECTRON EXTRACTION LAYER}

The p-i-n structured PSC usually shows no hysteresis and is easier to prepare a flexible device. The $\mathrm{p}-\mathrm{i}-\mathrm{n}$ structured PSC has used [6,6]-phenyl C61 butyric acid methyl ester (PCBM) (Supplementary Figure 2A) (Figure 1F) and C60 (Figure 1G) as n-type EEL owing to its high electron mobility (Kuang et al., 2015). In order to further improve the PCE of the p-i-n structured PSC, the perovskite/PCBM heterojunction solar cell can be fabricated by a solvent engineering method (Figure 1H). The perovskite precursor solution contained $\mathrm{PbI}_{2}, \mathrm{PbCl}_{2}$, and $\mathrm{CH}_{3} \mathrm{NH}_{3} \mathrm{I}$ in DMSO/GBL solvent. PCBM solution was dissolved in chlorobenzene with various concentrations. After the perovskite precursor solution was spin coated on the substrate, the PCBM solution was injected on the perovskite film. The perovskite/PCBM films were annealed at $100^{\circ} \mathrm{C}$ for $20 \mathrm{~min}$. The perovskite/PCBM heterojunction can improve the perovskite absorber quality and can increase charge extraction. Notably, adding PCBM during the baking procedure for perovskite absorber can form two separated EELs simultaneously, which effectively reduces the processing time. The champion device has exhibited a PCE of $17.8 \%$, which is higher than that of the reference device (13.7\%) (Zhou et al., 2018).

On the other hand, owing to the poor solubility of PCBM in DMF solvents, PCBM modification by fluorination can increase the solubility in the perovskite precursor. For the perovskite/fluorinated PCBM precursor solution, the fluorinated PCBM was directly added into the perovskite precursor solution. The perovskite/fluorinated PCBM precursor solution was spin coated on PEDOT:PSS film. The perovskite/fluorinated PCBM film was annealed at $100^{\circ} \mathrm{C}$ for $3 \mathrm{~min}$ to form the bulk heterojunction active layer. The fluorinated PCBM has shown to reduce the surface defects and to enhance the current density of PSC. The bulk heterojunction device with fluorinated PCBM has achieved a PCE of $16.2 \%$ with long-term stability (Supplementary Figure 2B) (Chang et al., 2018).

In order to enhance the fill factor of PSC, the perovskitePCBM bulk heterojunction PSC has been fabricated by a lowtemperature two-step spin-coating method. PCBM has been used as an acceptor to fill the vacancies and grain boundaries of the perovskite absorber. The product has demonstrated high current density, high fill factor, and high PCE because of high conductivity, high mobility, and long diffusion length of charge carriers. The bulk heterojunction PSC has achieved a PCE of
$16.0 \%$, fill factor of $82 \%$, and without J-V hysteresis (Chiang and $\mathrm{Wu}, 2016)$.

Although fullerene compounds have been commonly used in p-i-n structured PSC, C60 has also been used as an EEL for p-i$n$ structured PSC recently. The C60 EEL with various thickness was deposited by vapor deposition in the evaporation chamber. Fluorescence microscopy and impedance spectroscopy have been used to investigate electron extraction behavior. The role of the C60 EEL can support electron extraction and collection. The PCE of PSC with $1 \mathrm{~nm}$ C60 EEL has achieved 18.0\%. J-V hysteresis has also been significantly eliminated due to reduced space charge accumulation at the interface (Supplementary Figure 2C) (Liu et al., 2018).

\section{ADVANTAGES AND DISADVANTAGES OF THE DIFFERENT APPROACHES}

As mentioned above, most of the EEL is prepared by spin coating method due to easy fabrication, low-cost, and solution process. However, the spin coating method is very difficult when preparing a large-area film as the non-uniform film can directly affect device performance. The advantages of chemical bath deposition are a simple experimental setup and good reproducibility. But chemical bath deposition often requires a large amount of solution. Although evaporation and sputtering technique can produce large-area and uniform film, such methods require high vacuum and expensive equipment. Pulsed laser deposition can deposit many materials with the same composition as the target materials. Nevertheless, the coverage of the films is difficult to control by pulsed laser deposition. Atomic layer deposition can grow different multilayer structures with high sensitivity and precision. However, the disadvantages of atomic layer deposition are a longer process time for film fabrication and expensive setup. This summary also shows that the advantages and disadvantages of various methods should be considered for EEL fabrication.

\section{CURRENT ISSUES AND FUTURE CHALLENGES FOR ELECTRON EXTRACTION LAYER}

For the traditional high-temperature process, the EEL exhibits uniform mesoporous structure and high crystallinity. Comparing to the high-temperature process, the low-temperature process shows many fascinating advantages. The photovoltaic performance of PSC with the low-temperature process can still maintain high efficiency due to (1) passivation of the perovskite absorber/EEL interface, (2) high conductivity of EEL, and (3) application of UV or plasma treatment for EEL coalescence. Furthermore, the low-temperature processed EEL has shown to eliminate the hysteresis (Wojciechowski et al., 2014; Hou et al., 2015; Jeong et al., 2016; Tan et al., 2017; Wang et al., 2017a). When selecting EEL, several essential properties should be considered: (1) good electron mobility, (2) wide bandgap, and (3) band alignment with perovskite absorber. EEL with good electron mobility can facilitate the electron collection. For n-i-p 
structured PSC, the wide bandgap EEL is selected to facilitate the absorption behavior of perovskite absorber. With the proper band alignment, it can promote electron transfer from perovskite active layer to EEL and can block holes to avoid recombination. If the above issues can all be satisfied and the existence of $\mathrm{J}-\mathrm{V}$ hysteresis be eliminated, PSC with low-temperature process EEL can achieve a breakthrough in solar energy technology and realize commercialization.

\section{CONCLUSIONS}

In this mini-review, we summarized the metal oxide-based and fullerene compound-based EEL for PSC. Many n-type materials used for EEL, including $\mathrm{TiO}_{2}, \mathrm{ZnO}, \mathrm{SnO}_{2}, \mathrm{WO}_{\mathrm{x}}, \mathrm{CeO}_{\mathrm{x}}, \mathrm{Nb}_{2} \mathrm{O}_{5}$, PCBM, and C60 have been thoroughly introduced. In addition, all these alternative materials for EEL can be fabricated under low-temperature process and can achieve PCE of over $20 \%$. Using a low-temperature process to produce high-performance PSC is a major breakthrough. However, there are two issues that must be overcome before commercialization. The first one is the fast degradation phenomenon under humidity or constant irradiation, and the second is the hysteresis phenomena that can cause inaccurate estimation of PCE. The low-temperature

\section{REFERENCES}

Anaraki, E. H., Kermanpur, A., Steier, L., Domanski, K., Matsui, T., Tress, W., et al. (2016). Highly efficient and stable planar perovskite solar cells by solution-processed tin oxide. Energy Environ. Sci. 9, 3128-3134. doi: 10.1039/C6EE02390H

Azmi, R., Hwang, S., Yin, W., Kim, T.-W., Ahn, T. K., and Jang, S.-Y. (2018). High efficiency low-temperature processed perovskite solar cells integrated with alkali metal doped $\mathrm{ZnO}$ electron transport layers. ACS Energy Lett. 3, 1241-1246. doi: 10.1021/acsenergylett.8b00493

Bu, T., Shi, S., Li, J., Liu, Y., Shi, J., Chen, L., et al. (2018). Lowtemperature presynthesized crystalline tin oxide for efficient flexible perovskite solar cells and modules. ACS Appl. Mater. Interfaces 10, 14922-14929. doi: 10.1021/acsami.8b02624

Chan, S.-H., Wu, M.-C., Lee, K.-M., Chen, W.-C., Lin, T.-H., and Su, W.-F. (2017). Enhancing perovskite solar cell performance and stability by doping barium in methylammonium lead halide. J. Mater. Chem. A 5, 18044-18052. doi: 10.1039/C7TA05720B

Chang, C.-Y., Wang, C.-P., Raja, R., Wang, L., Tsao, C.-S., and Su, W.-F. (2018). High-efficiency bulk heterojunction perovskite solar cell fabricated by onestep solution process using single solvent: synthesis and characterization of material and film formation mechanism. J. Mater. Chem. A 6, 4179-4188. doi: 10.1039/C7TA07939G

Che, M., Zhu, L., Zhao, Y. L., Yao, D. S., Gu, X. Q., Song, J., et al. (2016). Enhancing current density of perovskite solar cells using $\mathrm{TiO}_{2}-\mathrm{ZrO}_{2}$ composite scaffold layer. Mater. Sci. Semicond. Process. 56, 29-36. doi: 10.1016/j.mssp.2016. 07.003

Chen, S.-H., Chan, S.-H., Lin, Y.-T., and Wu, M.-C. (2019). Enhanced power conversion efficiency of perovskite solar cells based on mesoscopic Ag-doped $\mathrm{TiO}_{2}$ electron transport layer. Appl. Surf. Sci. 469, 18-26. doi: 10.1016/j.apsusc.2018.10.256

Chen, X., Tang, L. J., Yang, S., Hou, Y., and Yang, H. G. (2016). A lowtemperature processed flower-like $\mathrm{TiO}_{2}$ array as an electron transport layer for high-performance perovskite solar cells. J. Mater. Chem. A 4, 6521-6526. doi: 10.1039/C6TA00893C

Chen, Y., Meng, Q., Zhang, L., Han, C., Gao, H., Zhang, Y., et al. (2018). $\mathrm{SnO}_{2}$-based electron transporting layer materials for perovskite process can effectively reduce production costs and energy waste. After addressing these issues, the commercialization of the low cost and flexible PSC is just around the corner.

\section{AUTHOR CONTRIBUTIONS}

S-HC wrote the submitted this mini-review. Y-HC revised and communicated the manuscript. M-CW supervised and wrote the manuscript.

\section{ACKNOWLEDGMENTS}

Financial support was obtained from Ministry of Science and Technology of Taiwan (Project Nos. 106-2221-E-182057-MY3 and 107-2119-M-002-012), Chang Gung University (QZRPD181), and Chang Gung Memorial Hospital, Linkou (CMRPD2H0171 and BMRPC74) are highly appreciated.

\section{SUPPLEMENTARY MATERIAL}

The Supplementary Material for this article can be found online at: https://www.frontiersin.org/articles/10.3389/fmats. 2019.00057/full\#supplementary-material

solar cells: a review of recent progress. J. Energy Chem. 35, 144-167. doi: 10.1016/j.jechem.2018.11.011

Chiang, C.-H., and Wu, C.-G. (2016). Bulk heterojunction perovskitePCBM solar cells with high fill factor. Nat. Photonics 10, 196-200. doi: 10.1038 /nphoton. 2016.3

Dou, B., Whitaker, J. B., Bruening, K., Moore, D. T., Wheeler, L. M., Ryter, J., et al. (2018). Roll-to-roll printing of perovskite solar cells. ACS Energy Lett. 3, 2558-2565. doi: 10.1021/acsenergylett.8b01556

Fan, P., Zheng, D., Zheng, Y., and Yu, J. (2018). Efficient and stable planar p-i-n perovskite solar cells by doping tungsten compound into PEDOT:PSS to facilitate perovskite crystalline. Electrochim. Acta 283, 922-930. doi: 10.1016/j.electacta.2018.07.029

Gaspar, D., Pereira, L., Gehrke, K., Galler, B., Fortunato, E., and Martins, R. (2017). High mobility hydrogenated zinc oxide thin films. Sol. Energy Mater. Sol. Cells 163, 255-262. doi: 10.1016/j.solmat.2017.01.030

Heo, J. H., Han, H. J., Kim, D., Ahn, T. K., and Im, S. H. (2015). Hysteresis-less inverted $\mathrm{CH}_{3} \mathrm{NH}_{3} \mathrm{PbI}_{3}$ planar perovskite hybrid solar cells with $18.1 \%$ power conversion efficiency. Energy Environ. Sci. 8, 1602-1608. doi: 10.1039/C5EE00120J

Hou, Y., Quiroz, C. O. R., Scheiner, S., Chen, W., Stubhan, T., Hirsch, A., et al. (2015). Low-temperature and hysteresis-free electron-transporting layers for efficient, regular, and planar structure perovskite solar cells. Adv. Energy Mater. 5:1501056. doi: 10.1002/aenm.201501056

Jeong, I., Jung, H., Park, M., Park, J. S., Son, H. J., Joo, J., et al. (2016). A tailored $\mathrm{TiO}_{2}$ electron selective layer for high-performance flexible perovskite solar cells via low temperature UV process. Nano Energy 28, 380-389. doi: 10.1016/j.nanoen.2016.09.004

Jiang, Q., Zhang, L., Wang, H., Yang, X., Meng, J., Liu, H., et al. (2016). Enhanced electron extraction using $\mathrm{SnO}_{2}$ for high-efficiency planarstructure $\mathrm{HC}\left(\mathrm{NH}_{2}\right)_{2} \mathrm{PbI}_{3}$-based perovskite solar cells. Nat. Energy 2:16177. doi: 10.1038/nenergy.2016.177

Kuang, C., Tang, G., Jiu, T., Yang, H., Liu, H., Li, B., et al. (2015). Highly efficient electron transport obtained by doping PCBM with graphdiyne in planar-heterojunction perovskite solar cells. Nano Lett. 15, 2756-2762. doi: 10.1021/acs.nanolett.5b00787

Kuang, Y., Zardetto, V., Van Gils, R., Karwal, S., Koushik, D., Verheijen, M. A., et al. (2018). Low-temperature plasma-assisted atomic-layer-deposited $\mathrm{SnO}_{2}$ as 
an electron transport layer in planar perovskite solar cells. ACS Appl. Mater. Interfaces 10, 30367-30378. doi: 10.1021/acsami.8b09515

Ling, X., Yuan, J., Liu, D., Wang, Y., Zhang, Y., Chen, S., et al. (2017). Roomtemperature processed $\mathrm{Nb}_{2} \mathrm{O}_{5}$ as the electron-transporting layer for efficient planar perovskite solar cells. ACS Appl. Mater. Interfaces 9, 23181-23188. doi: 10.1021/acsami.7b05113

Liu, D., Wang, Q., Traverse, C. J., Yang, C., Young, M., Kuttipillai, P. S., et al. (2018). Impact of ultrathin C60 on perovskite photovoltaic devices. ACS Nano 12, 876-883. doi: 10.1021/acsnano.7b08561

Liu, X., Yang, Z., Chueh, C.-C., Rajagopal, A., Williams, S. T., Sun, Y., et al. (2016). Improved efficiency and stability of $\mathrm{Pb}-\mathrm{Sn}$ binary perovskite solar cells by $\mathrm{Cs}$ substitution. J. Mater. Chem. A 4, 17939-17945. doi: 10.1039/C6TA07712A

Mahmud, M. A., Elumalai, N. K., Upama, M. B., Wang, D., Chan, K. H., Wright, M., et al. (2017). Low temperature processed $\mathrm{ZnO}$ thin film as electron transport layer for efficient perovskite solar cells. Sol. Energy Mater. Sol. Cells 159, 251-264. doi: 10.1016/j.solmat.2016.09.014

Mali, S. S., Kim, H., Kim, H. H., Shim, S. E., and Hong, C. K. (2018). Nanoporous ptype NiOx electrode for $\mathrm{p}-\mathrm{i}-\mathrm{n}$ inverted perovskite solar cell toward air stability. Mater. Today 21, 483-500. doi: 10.1016/j.mattod.2017.12.002

Saliba, M., Matsui, T., Domanski, K., Seo, J.-Y., Ummadisingu, A., Zakeeruddin, S. M., et al. (2016a). Incorporation of rubidium cations into perovskite solar cells improves photovoltaic performance. Science. 354, 206-209. doi: 10.1126/science.aah5557

Saliba, M., Matsui, T., Seo, J.-Y., Domanski, K., Correa-Baena, J.-P., Nazeeruddin, M. K., et al. (2016b). Cesium-containing triple cation perovskite solar cells: improved stability, reproducibility and high efficiency. Energy Environ. Sci. 9, 1989-1997. doi: 10.1039/c5ee03874j

Schulze, P. S. C., Bett, A. J., Winkler, K., Hinsch, A., Lee, S., Mastroianni, S., et al. (2017). Novel low-temperature process for perovskite solar cells with a mesoporous $\mathrm{TiO}_{2}$ scaffold. ACS Appl. Mater. Interfaces 9, 30567-30574. doi: 10.1021/acsami.7b05718

Song, J., Liu, L., Wang, X.-F., Chen, G., Tian, W., and Miyasaka, T. (2017). Highly efficient and stable low-temperature processed $\mathrm{ZnO}$ solar cells with triple cation perovskite absorber. J. Mater. Chem. A 5, 13439-13447. doi: 10.1039/C7TA03331A

Subbiah, A. S., Mathews, N., Mhaisalkar, S., and Sarkar, S. K. (2018). Novel plasma-assisted low-temperature-processed $\mathrm{SnO}_{2}$ thin films for efficient flexible perovskite photovoltaics. ACS Energy Lett. 3, 1482-1491. doi: 10.1021/acsenergylett.8b00692

Tan, H., Jain, A., Voznyy, O., Lan, X., García De Arquer, F. P., Fan, J. Z., et al. (2017). Efficient and stable solution-processed planar perovskite solar cells via contact passivation. Science 355, 722-726. doi: 10.1126/science. aai9081

Wang, K., Shi, Y., Dong, Q., Li, Y., Wang, S., Yu, X., et al. (2015). Low-temperature and solution-processed amorphous $\mathrm{WO}_{\mathrm{X}}$ as electronselective layer for perovskite solar cells. J. Phys. Chem. Lett. 6, 755-759. doi: 10.1021/acs.jpclett.5b00010
Wang, L., Liu, F., Liu, T., Cai, X., Wang, G., Ma, T., et al. (2017a). Low-temperature processed compact layer for perovskite solar cells with negligible hysteresis. Electrochim. Acta 235, 640-645. doi: 10.1016/j.electacta.2017.03.145

Wang, X., Deng, L.-L., Wang, L.-Y., Dai, S.-M., Xing, Z., Zhan, X.-X., et al. (2017b). Cerium oxide standing out as an electron transport layer for efficient and stable perovskite solar cells processed at low temperature. J. Mater. Chem. A 5, 1706-1712. doi: 10.1039/C6TA07541J

Wojciechowski, K., Saliba, M., Leijtens, T., Abate, A., and Snaith, H. J. (2014). Sub$150^{\circ} \mathrm{C}$ processed meso-superstructured perovskite solar cells with enhanced efficiency. Energy Environ. Sci. 7, 1142-1147. doi: 10.1039/C3EE43707H

Wu, M.-C., Chan, S.-H., Jao, M.-H., and Su, W.-F. (2016). Enhanced shortcircuit current density of perovskite solar cells using $\mathrm{Zn}$-doped $\mathrm{TiO}_{2}$ as electron transport layer. Sol. Energy Mater. Sol. Cells 157, 447-453. doi: 10.1016/j.solmat.2016.07.003

Wu, M.-C., Chan, S.-H., Lee, K.-M., Chen, S.-H., Jao, M.-H., Chen, Y.-F., et al. (2018a). Enhancing the efficiency of perovskite solar cells using mesoscopic zinc-doped $\mathrm{TiO}_{2}$ as the electron extraction layer through band alignment. $J$. Mater. Chem. A 6, 16920-16931. doi: 10.1039/C8TA05291C

Wu, M.-C., Liao, Y.-H., Chan, S.-H., Lu, C.-F., and Su, W.-F. (2018b). Enhancing organolead halide perovskite solar cells performance through interfacial engineering using Ag-doped $\mathrm{TiO}_{2}$ hole blocking layer. Solar RRL 2:1800072. doi: 10.1002/solr.201800072

Yang, B., Mahjouri-Samani, M., Rouleau, C. M., Geohegan, D. B., and Xiao, K. (2016). Low temperature synthesis of hierarchical $\mathrm{TiO}_{2}$ nanostructures for high performance perovskite solar cells by pulsed laser deposition. Phys. Chem. Chem. Phys. 18, 27067-27072. doi: 10.1039/C6CP02896A

Zhang, J., Hultqvist, A., Zhang, T., Jiang, L., Ruan, C., Yang, L., et al. (2017). $\mathrm{Al}_{2} \mathrm{O}_{3}$ underlayer prepared by atomic layer deposition for efficient perovskite solar cells. ChemSusChem 10, 3810-3817. doi: 10.1002/cssc.201701160

Zhang, P., Wu, J., Zhang, T., Wang, Y., Liu, D., Chen, H., et al. (2018). Perovskite solar cells with $\mathrm{ZnO}$ electron-transporting materials. Adv. Mater. 30:1703737. doi: 10.1002/adma.201703737

Zhou, L., Chang, J., Liu, Z., Sun, X., Lin, Z., Chen, D., et al. (2018). Enhanced planar perovskite solar cell efficiency and stability using a perovskite/PCBM heterojunction formed in one step. Nanoscale 10, 3053-3059. doi: 10.1039/C7NR07753J

Conflict of Interest Statement: The authors declare that the research was conducted in the absence of any commercial or financial relationships that could be construed as a potential conflict of interest.

Copyright (c) 2019 Chan, Chang and Wu. This is an open-access article distributed under the terms of the Creative Commons Attribution License (CC BY). The use, distribution or reproduction in other forums is permitted, provided the original author(s) and the copyright owner(s) are credited and that the original publication in this journal is cited, in accordance with accepted academic practice. No use, distribution or reproduction is permitted which does not comply with these terms. 